EDITORIAL

\title{
Revista Médica Hondureña: Aniversario Noventa en tiempos de pandemia
}

\author{
Revista Médica Hondureña: Ninetieth Anniversary in pandemic times
}

En 2020, año de la pandemia producida por el nuevo coronavirus SARS-CoV-2 (COVID-19), la Revista Médica Hondureña cumple noventa años de publicación ininterrumpida; fundada en noviembre de 1929, publicó su primer número en mayo de 1930. Desde su creación, ha evolucionado en varios aspectos: periodicidad mensual, bimestral y trimestral, hasta la actual que es semestral; soporte inicial impresa y actualmente predomina la electrónica (http://www.bvs.hn/RMH/, https:// revistamedicahondurena.hn/). Hasta los años noventa del siglo pasado, la Revista era irregular en su formato y contenido. A finales de los años noventa en adelante, se toman en cuenta de manera sistemática parámetros de normalización dirigidos a alcanzar y mantener características bibliométricas de calidad que permitan la indización de la Revista en índices internacionales, lo cual contribuye a visibilizar la actividad académica y científica en el país y su mejora continua. Estos parámetros incluyen entre otros, regularidad en la publicación, revisión por pares, registro ISSN actualizado, estructura estandarizada de los artículos de acuerdo al tipo y las instrucciones para autor detalladas según pautas internacionales.

A través de la Revista aprendemos de las patologías prevalentes, relevantes en el país, y acerca del sistema sanitario que las atiende; también conocemos de la comunidad de profesionales, de las organizaciones y eventos involucrados en el sistema, así como su evolución a lo largo de las décadas. Por medio de la Revista hemos conocido de la pandemia de sida, sus complicaciones y la respuesta de salud pública; ${ }^{1}$ al igual que las epidemias regionales de cólera, dengue y zika; ${ }^{2-4}$ y el grave problema sanitario que representan las enfermedades crónicas no transmisibles. ${ }^{5}$ En este numero se publican tres artículos que conmemoran el aniversario de manera especial. Uno de ellos hace un recuento de las publicaciones sobre parasitosis (Kaminsky RG, pág. 8-15) otro analiza la rehabilitación como intervención terapéutica en los casos clínicos publicados (Molina $\mathrm{E}$ et al, pág. 16-21) y otro analiza las publicaciones sobre ética de la investigación (Espinoza E et al, pág. 33-37). Estos son ejemplos de la valiosa información disponible para análisis desde la Revista.
En el actual contexto de la pandemia de COVID-19, también se publican dos artículos que abordan aspectos relevantes de la misma. Uno es el Editorial de la Dra. Helga Codina quien hace importantes reflexiones sobre el manejo de la pandemia (pág. 6 ). El otro es un artículo de opinión sobre las enfermedades cardiovasculares en el contexto de la pandemia, que además hace un llamado al personal de salud y a la población a implementar medidas para mantener la salud cardiovascular y metabólica y para los que ya padecen una enfermedad de este tipo, asegurarse de estar adecuadamente controlados (Moncada G, pág. 55-56).

Es evidente el impacto de la pandemia en todos los ámbitos de la vida a nivel global, en la región de las Américas y en países como el nuestro. ${ }^{6}$ En Honduras, particularmente importante ha sido el impacto negativo en un ya debilitado e insuficiente sistema sanitario y en el desarrollo socioeconómico del país, y lo que se visualiza en el mediano y largo plazo. Aunque no es momento de festejo, la mejor celebración del Aniversario 90 de la Revista Médica Hondureña es su continuada vigencia reflejada en las publicaciones que compartimos en este número y en las que compartiremos próximamente en el Suplemento 90 Aniversario.

Jackeline Alger, MD, PhD

Directora

Revista Médica Hondureña

\section{REFERENCIAS}

1. Alvarado T. Síndrome de Inmunodeficiencia Adquirida. SIDA: Consideraciones históricas, epidemiológicas, teológicas, inmunológicas, clínicas, terapéuticas y de control. Rev Méd Hondur. 1985;53:177-189.

2. El cólera: un enemigo en potencia. Rev Méd Hondur. 1991;59:61.

3. Figueroa M, Pereira R, Gutiérrez H, Mejía Carmen, Padilla N. La epidemia de dengue en Honduras 1978-1980. Rev Méd Hondur. 1981;49:28-33.

4. Rodríguez Gudiel H. El Zika llegó para quedarse. Rev Méd Hondur. 2016;84:83.

5. Duarte RM. Obesidad y sobrepeso: una epidemia mundial. Rev Méd Hondur. 2015;83:5-6.

6. Naciones Unidas. Comisión Económica para América Latina y el Caribe. América Latina y el Caribe ante la pandemia del COVID-19. Efectos económicos y sociales. Santiago de Chile: CEPAL; 2020. 